\title{
Resíduos de Solow Industriais: um Estudo Empírico para o Brasil*
}

\section{Industrial Solow Residuals: an Empirical Study for Brazil}

Matheus Albergaria de Magalhães**

Resumo: Neste artigo, estudamos as propriedades cíclicas de taxas de variação de medidas de produtividade total dos fatores ("Resíduos de Solow") para a indústria brasileira. Para tanto, procuramos verificar se diferenças na metodologia de construção das medidas de produtividade consideradas afetam suas propriedades estatísticas. Os resultados obtidos demonstram que tais propriedades são sensíveis à metodologia empregada. Em particular, no caso da amostra analisada, obtemos três resultados básicos: (i) medidas de produtividade corrigidas são menos correlacionadas com medidas de produção industrial, quando comparadas com medidas de produtividade não corrigidas; (ii) medidas onde a correção é feita a partir do uso da variável "consumo industrial de energia elétrica" apresentam uma volatilidade inferior à volatilidade da produção industrial, enquanto que medidas nas quais a correção é feita a partir do uso da variável "utilização da capacidade instalada" apresentam uma volatilidade superior; (iii) apenas medidas em que a correção é feita a partir do uso de taxas variáveis de utilização da capacidade instalada obedecem à propriedade de invariância de Hall-Evans, podendo ser caracterizadas como exógenas. Esses resultados demonstram a importância da metodologia empregada na construção de medidas de produtividade, bem como a importância de taxas variáveis de utilização da capacidade instalada no caso de horizontes correspondentes a ciclos de negócios.

Palavras-chave: Resíduo de Solow. Choques tecnológicos. Ciclos de negócios.

O autor agradece os comentários e as sugestões de Afonso Ferreira, André Chagas, Carlos Assato, Denisard Alves, Fernando Postali, Gilberto Tadeu Lima, Gílson Geraldino Jr., Paulo Picchetti e aos participantes de um seminário de Economia ocorrido na Fundação Escola de Comércio Álvares Penteado (FECAP). Um agradecimento especial a Fábio Kanczuk e Martin Eichenbaum, por terem fornecido seus dados originais para fins de replicação. O autor agradece ainda a Sasakawa Young Leader Foundation Fellowship (SYLFF), por suporte parcial a esta pesquisa. Vale a ressalva de que as opiniões aqui contidas não refletem as opiniões da SYLFF, do IJSN, ou de algum dos membros dessas duas instituições. Do mesmo modo, vale a ressalva usual de que os erros e as idiossincrasias contidos neste artigo são de inteira responsabilidade do autor.

** Coordenador de Estudos Econômicos, Rede de Estudos Macroeconômicos (MACRO) do Instituto Jones dos Santos Neves (IJSN). E-mail: matheus@ijsn.es.gov.br 
Abstract: In this paper, we study the cyclical properties of total-factor-productivity (TFP) rates ("Solow residuals") for the Brazilian industry. In doing so, we check if methodological differences related to the construction of TFP measures can affect their statistical properties. The results obtained show that such properties are sensitive to the methodology employed. In particular, in the case of our sample, we obtain three main results: (i) corrected productivity measures are less correlated with industrial production measures when compared to non-corrected measures; (ii) corrected measures, where correction is done through the use of industrial energy consumption, are less volatile than industrial production measures, while the opposite is true for corrected measures where correction is done through capacity utilization rates; (iii) corrected measures where correction is made through the use of capacity utilization rates are the only measures which obey the Hall-Evans Invariance Property and they can be characterized as exogenous. These results show the importance of methodological issues related to the construction of productivity measures as well as the importance of variable capacity utilization rates in the case of business-cycle horizons.

Keywords: Solow residual. Technology shocks. Business cycles.

JEL Classification: E32; C32; C52.

\section{1 lntrodução}

Entender as origens das flutuações econômicas sempre constituiu um desafio básico para os macroeconomistas. Em particular, compreender os efeitos de choques específicos e sua propagação pela economia tem sido uma das tarefas mais recorrentes na área de Macroeconomia, com esforços de pesquisa remontando pelo menos até o trabalho de autores como Frisch e Slutsky, por exemplo (COOLEY; PRESCOTT, 1995).

Uma linha de pesquisa que ganhou notoriedade nas últimas décadas foi a agenda de pesquisa relacionada a modelos Real-Business-Cycle (RBC) (KYDLAND; PRESCOTT, 1982; LONG; PLOSSER, 1983). Os modelos iniciais desse tipo enfatizavam a importância de choques tecnológicos e de seus efeitos sobre as demais variáveis macroeconômicas. Em particular, esses modelos correspondiam a versões modificadas do modelo neoclássico de crescimento, em que se procurava checar a resposta dos principais agregados macroeconômicos (produto, consumo, investimento, estoque de capital e horas trabalhadas) a variações na tecnologia de produção da economia. O objetivo básico desses primeiros modelos era responder à seguinte pergunta: qual é a porcentagem 
das flutuações no produto agregado que pode ser atribuída a choques tecnológicos? ${ }^{1}$

Uma das primeiras tentativas de verificação empírica desses modelos utilizou a taxa de variação de medidas de produtividade total dos fatores (o "resíduo de Solow") como proxy para choques tecnológicos incidentes sobre a economia (PRESCOTT, 1986). No caso, esse autor estudou os efeitos de um choque tecnológico sobre a economia artificial de um modelo correspondente a uma versão modificada do modelo de Solow (SOLOW, 1956). Para tanto, analisou as propriedades estatísticas de uma medida de produtividade relacionada à economia real (coeficiente de autocorrelação de primeira ordem e variância das inovações) e seus efeitos sobre uma economia artificial. Os resultados obtidos por Prescott (1986) revelaram-se surpreendentes: no caso, o resíduo de Solow seria responsável por $75 \%$ das flutuações econômicas nos Estados Unidos ao longo do período pós-guerra.

O objetivo deste artigo é verificar as propriedades estatísticas de medidas de produtividade total dos fatores (PTF) construídas a partir de metodologias distintas. Especificamente, estamos interessados em responder à seguinte pergunta: diferenças metodológicas na construção dessas medidas podem afetar as propriedades empíricas de taxas de variação da PTF (resíduos de Solow)? Nossos resultados demonstram que, no caso de dados industriais brasileiros, a resposta à questão anterior é positiva. Resíduos de Solow, calculados a partir de metodologias diferentes, apresentam padrões empíricos marcadamente distintos no caso de horizontes correspondentes a ciclos de negócios. Em particular, obtemos três resultados básicos:

(i) Medidas de produtividade corrigidas (onde a correção é feita via consumo industrial de energia elétrica ou via utilização da capacidade instalada) são menos correlacionadas com medidas de produção industrial, quando comparadas com medidas de produtividade não corrigidas (calculadas de acordo com a metodologia tradicional).

(ii) Medidas nas quais a correção é feita a partir do uso da variável "consumo industrial de energia elétrica" apresentam uma volatilidade inferior à volatilidade da produção industrial, enquanto que medidas em que a correção é feita a partir do uso da variável "utilização da capacidade instalada" apresentam uma volatilidade superior.

$1 \quad$ Para mais informações sobre esses modelos, ver, a título de exemplo, Stadler (1994), Cooley (1995), King e Rebelo (2000) e Rebelo (2005). Magalhães (2005) equivale a uma resenha crítica em português dessa agenda de pesquisa. No caso desses modelos, considera-se, em geral, um conceito amplo de choque tecnológico. Em termos gerais, choques tecnológicos nesses modelos podem ser interpretados como qualquer fator tido como fora da influência de firmas individuais na economia (HANSEN, 1994). 
(iii) Apenas medidas nas quais a correção é feita a partir do uso de taxas variáveis de utilização da capacidade instalada obedecem à propriedade de invariância de Hall-Evans (a ser definida adiante), podendo ser caracterizadas como exógenas.

Os resultados obtidos são robustos a distintas questões de especificação, como a aplicação de diferentes filtros às séries analisadas e o número de defasagens empregadas em testes de Granger-causalidade. Esses resultados são interessantes pela sugestão da importância de questões metodológicas quando da construção de medidas de produtividade empregadas em estudos aplicados. Do mesmo modo, vemos os resultados aqui reportados como sugestivos da importância da variável "utilização da capacidade instalada" para o estudo dos ciclos de negócios, um ponto já ressaltado por autores como Bils e Cho (1994) e King e Rebelo (2000), por exemplo.

Duas observações preliminares, no entanto, fazem-se necessárias antes de procedermos. Primeiramente, dada a diversidade de contribuições teóricas relacionadas a modelos RBC em termos de choques incidentes sobre a economia e mecanismos de propagação, é importante ressaltarmos que os resultados aqui apresentados não representam uma evidência definitiva relacionada a esses modelos. Ainda assim, esperamos que esses resultados possam ser úteis no sentido de estimular a construção de modelos teóricos condizentes com algumas das regularidades empíricas aqui descritas.

Em segundo lugar, é importante notar que este é um exercício empírico restrito à indústria brasileira, apenas. Assim, é preciso cuidado quando da extrapolação dos resultados aqui apresentados. Esperamos que a pesquisa futura encarregue-se de confirmar ou não nossos resultados a partir do uso de bases de dados e períodos amostrais distintos. De qualquer forma, vale a pena ressaltar que nossos resultados estão de acordo com outros resultados reportados na literatura empírica internacional sobre o tema (EVANS, 1992; OTTO, 1999; PAQUET; ROBIDOUX, 2001). Em última instância, o presente artigo pode ser visto como uma contribuição nas áreas de Macroeconomia e Organização Industrial empírica, basicamente. ${ }^{2}$

O artigo está dividido da seguinte maneira: na segunda seção, descrevemos algumas das contribuições relacionadas à importância empírica de mensuração do resíduo de Solow, como forma de motivarmos o tema. Na terceira seção, descrevemos a base de dados e a metodologia de construção das principais variáveis utilizadas na análise

2 Para um exemplo de uma contribuição que também tange ambas as áreas citadas, embora possua objetivos nitidamente distintos aos nossos, ver Midrigan (2010). 
empírica subsequente. A quarta seção contém os resultados obtidos, enquanto a quinta seção expõe os resultados de testes de robustez. Finalmente, a sexta seção contém as conclusões do artigo, bem como algumas sugestões de pesquisa futura.

\section{Referencial Teórico}

Interessado em verificar a adequação empírica do modelo neoclássico de crescimento, Solow (1957) propôs um método simples de segregar variações per capita do produto devidas à mudança tecnológica daquelas devidas a mudanças na disponibilidade dos fatores de produção (capital e trabalho). ${ }^{3}$ Basicamente, esse autor estava interessado em verificar empiricamente a importância dos fatores de produção e do componente tecnológico para o crescimento econômico americano. Usando dados agregados, Solow obteve um resultado surpreendente à primeira vista: cerca de $80 \%$ da variação do produto agregado devia-se a variações na tecnologia, ao invés de variações nos insumos de produção. Inicialmente, esperava-se que a contribuição do componente tecnológico da função de produção fosse pequena para o crescimento econômico, uma vez que os insumos fossem adequadamente mensurados. Uma consequência direta desse resultado obtido por Solow foi que a maior parte da pesquisa posterior relacionada ao tema passou a dedicar-se a questões relacionadas à mensuração do resíduo. ${ }^{4}$

Por sua vez, Prescott (1986) utilizou o resíduo de Solow como uma aproximação empírica para representar choques tecnológicos em modelos RBC. No caso, o autor procurava responder à seguinte questão: qual é a parcela de choques tecnológicos (medidos via resíduo de Solow) que é responsável por oscilações de curto prazo no produto agregado? Os resultados obtidos por Prescott também revelaram-se surpreendentes: no caso, o resíduo de Solow seria responsável por cerca de $75 \%$ das flutuações econômicas de curto prazo nos Estados Unidos ao longo do período pós-guerra. Este resultado gerou bastante controvérsia na época da publicação desse artigo, uma vez que parecia favorecer de forma considerável a hipótese acerca da importância de fatores reais

3 Para uma exposição formal do método proposto por Solow (1957), ver o Apêndice B deste trabalho.

4 Para uma contextualização histórica dos desenvolvimentos posteriores a Solow (1957), ver Griliches (1996). Para um exemplo de um estudo que utiliza a metodologia proposta por Solow para analisar fenômenos relacionados a ciclos de negócios, ver Basu, Fernald e Kimball (1998). 
na geração de flutuações econômicas, em detrimento de fatores nominais, como a moeda, por exemplo, tida até então como extremamente importante nesse processo.

Utilizando dados desagregados da indústria americana ao longo do período 1953/1984, Hall (1988; 1990) desenvolveu uma abordagem dual relacionada ao resíduo de Solow para checar a validade empírica de duas hipóteses básicas: (a) a igualdade entre preço e custo marginal, e (b) a ocorrência de retornos constantes de escala para essas indústrias. O autor baseou sua análise na proposição por ele denominada de "propriedade de invariância do resíduo de Solow", que diz que: "[...] Under competition and constant returns to scale, the Solow residual is uncorrelated with all variables known neither to be causes of productivity shifts nor to be caused by productivity shifts" (HALL, 1988, p. 924).

A lógica do teste proposto por Hall é a seguinte: se taxas de variação de medidas de produtividade representam variações cíclicas na tecnologia de uma economia de forma acurada, então essas medidas não deveriam ser correlacionadas com variáveis instrumentais previamente escolhidas. Ou seja, a hipótese de identificação do autor é que mudanças efetivas na produtividade não são correlacionadas com movimentos nas variáveis instrumentais consideradas, podendo-se, em última instância, testar conjuntamente as hipóteses de competição e retornos constantes de escala a partir do teste da hipótese de que a covariância do resíduo de Solow com o instrumento considerado seja nula. No caso, Hall $(1988 ; 1990)$ considera três variáveis instrumentais: gastos militares, preços internacionais do petróleo e o partido político de presidentes americanos. Seus resultados apontam para a rejeição conjunta das hipóteses testadas, devido ao fato do resíduo de Solow mostrar-se correlacionado com as variáveis instrumentais consideradas. $\mathrm{Na}$ verdade, dada a lógica do teste empregado, caso o preço exceda o custo marginal na indústria, então o resíduo de Solow poderá exibir um padrão pró-cíclico, mesmo que a tecnologia de produção subjacente permaneça inalterada, o que demonstra sua inadequação como proxy para choques tecnológicos em modelos econômicos. A implicação principal deste trabalho é a seguinte: o resíduo de Solow pode não ser caracterizado como uma medida plenamente exógena, dada a sua correlação com as variáveis citadas, o que torna inadequado seu uso como proxy para choques tecnológicos no curto prazo.

Relacionado a essa última questão, há o estudo de Evans (1992), que procurou testar a precedência temporal de algumas variáveis macroeconômicas sobre o resíduo de Solow para os Estados Unidos ao longo do período 1957/1983. Usando dados trimestrais, o autor realiza testes de Granger-causalidade envolvendo uma medida de PTF 
e diversas variáveis macroeconômicas (conceito M1 de moeda, taxas de juros, índice de preços ao consumidor, gastos do governo e preços do petróleo). Para que a endogeneidade do resíduo de Solow seja comprovada, basta, segundo esse autor, que alguma das variáveis macroeconômicas citadas Granger-cause o resíduo de Solow. A partir de diferentes especificações, dois resultados básicos emergem: (a) o conceito de moeda empregado (M1), as taxas de juros e os gastos do governo Granger-causam a medida de PTF empregada no estudo; e (b) uma parte substancial dos impulsos relacionados à PTF (entre $25 \mathrm{e}$ 50 por cento) pode ser atribuída a variações de demanda agregada. ${ }^{5}$

Otto (1999) elabora um estudo semelhante ao de Evans (1992) relacionado à economia australiana. Usando dados trimestrais para o período 1959/1992, o autor também realiza testes de Granger-causalidade entre uma medida convencional do resíduo de Solow e algumas variáveis macroeconômicas. No caso, apesar desse autor usar algumas variáveis similares às variáveis usadas por Evans para o caso americano (preços do petróleo, gastos do governo e algumas medidas de taxa de juros), o autor também utiliza variáveis macroeconômicas que possam captar outros choques incidentes sobre uma pequena economia aberta (preços de commodities, termos de troca, PNB conjunto dos países do G-7, investimento do governo e o conceito M3 de moeda), conforme é o caso da economia australiana. Os resultados obtidos pelo autor indicam que a medida de produtividade empregada não pode ser tida como estritamente exógena, uma vez que é Granger-causada por variáveis como o índice de termos de troca, o PNB dos G-7 e duas das três medidas de juros consideradas na análise. A principal conclusão advinda desse estudo é que flutuações no resíduo de Solow australiano não refletem unicamente choques tecnológicos, podendo refletir também choques de demanda.

Paquet e Robidoux (2001) refizeram os testes de Hall (1988; 1990) e Evans (1992) para o Canadá com dados trimestrais ao longo do período 1970/1993. Consideram, entretanto, uma única diferença em relação a outros estudos empíricos do gênero: a importância da variável "utilização da capacidade instalada" no cálculo do resíduo de Solow. Assim, utilizam medidas do resíduo de Solow nas quais o fator capital é corrigido por variações na taxa de utilização da capacidade instalada. ${ }^{6}$ Seus

5 No que segue, nos referimos à propriedade de invariância do resíduo de Solow como "propriedade de invariância de Hall-Evans".

6 Em particular, os autores fazem uso de uma medida corrigida do estoque de capital, denotada por $K^{*}$ e obtida a partir da fórmula $\mathrm{K}^{*}=\mathrm{K}$ x UCI, onde $\mathrm{K}$ representa o estoque de capital, ao passo que UCI representa a medida de utilização da capacidade instalada empregada ao longo da análise. 
resultados mostram-se favoráveis às hipóteses de competição e retornos constantes de escala em nível agregado para a economia canadense no período considerado. Em termos da exogeneidade do resíduo de Solow, seus resultados são os seguintes: no caso da medida de produtividade não ajustada, os autores obtêm um resultado em que esta é Grangercausada por agregados monetários, pela taxa de juros e por um índice de preços; ao considerarem a medida corrigida por variações na taxa de utilização da capacidade instalada, entretanto, não conseguem rejeitar a hipótese de exogeneidade. Estes resultados demonstram a importância de se levar em conta taxas variáveis de utilização dos fatores na construção de medidas de produtividade.

Relacionado a esse último ponto, há o trabalho de Burnside e Eichenbaum (1996), que investiga a importância, em termos quantitativos, de taxas de utilização da capacidade instalada para modelos $\mathrm{RBC}$. Seus resultados, além de demonstrarem a importância desse fator como mecanismo de propagação de choques nesses modelos, também demonstram que, no caso de taxas de utilização variáveis ao longo do tempo, a volatilidade de choques tecnológicos necessária para a geração de ciclos passa a ser consideravelmente inferior em comparação a modelos RBC, em que não são consideradas taxas de utilização variáveis dos fatores de produção (cerca de 33\% inferior). No caso, as taxas de utilização passam a ser variáveis endógenas do modelo, o que faz com que ocorram diferenças significativas entre o choque tecnológico efetivo (não observável) e o resíduo de Solow mensurado (observável). Ou seja, os autores concluem que modelos RBC que usam o resíduo de Solow como proxy para variações na tecnologia de uma economia tendem a superestimar a proporção da variabilidade de choques tecnológicos responsável pela variabilidade do PNB americano.

Em Burnside, Eichenbaum e Rebelo (1996), os autores exploram mais detalhadamente esse ponto, utilizando medidas corrigidas do resíduo de Solow - tanto em nível agregado quanto desagregado - a partir do uso da variável "consumo industrial de energia elétrica" como proxy para os serviços do capital. Esses autores obtêm resultados nos quais suas medidas corrigidas, além de apresentarem uma volatilidade consideravelmente menor do que medidas tradicionais (cerca de $70 \%$ menor, no caso de dados trimestrais e anuais), também não são correlacionadas com a taxa de crescimento do produto. Esses resultados têm consequências diretas para modelos $\mathrm{RBC}$, uma vez que choques de produtividade passam a apresentar uma volatilidade bem menor do que aquela suposta em modelos iniciais do gênero. Consequentemente, para que choques com uma variação tão pequena possam gerar ciclos 
nas magnitudes usualmente observadas, é preciso que existam fortes mecanismos de propagação dos choques tecnológicos iniciais sobre a economia. ${ }^{7}$

\section{Base de Dados e Variáveis Empregadas na Análise}

Usando dados trimestrais relacionados à indústria brasileira ao longo do período 1985:01/2001:01, provenientes do Instituto Brasileiro de Geografia e Estatística (IBGE), construímos medidas de produtividade total dos fatores distintas. ${ }^{8} \mathrm{~A}$ Tabela 1 contém uma descrição das medidas empregadas na análise subsequente:

Tabela 1 - Variáveis Empregadas na Construção de Medidas de Produtividade

\begin{tabular}{c|c}
\hline Nome & Variáveis Empregadas \\
\hline TFPSTD & Produção Industrial, Horas Pagas e Estoque de Capital \\
TFPEE & Produção Industrial, Horas Pagas e Consumo Industrial de Energia Elétrica \\
TFPUCI & $\begin{array}{c}\text { Produção Industrial, Horas Pagas e Estoque de Capital multiplicado pela Util. } \\
\text { da Capac. Instalada (setor de Bens de Capital) }\end{array}$ \\
\hline
\end{tabular}

Fonte: Elaborada pelo autor com base nos dados do Instituto Brasileiro de Geografia e Estatística (2004), Eletrobras (2004) e Fundação Getúlio Vargas (2004).

A diferença entre essas medidas fica por conta do tratamento dado aos fatores de produção. A primeira medida de produtividade considerada (TFPSTD) equivale a uma aplicação direta da metodologia proposta originalmente por Solow (1957). Para representar a variável produto, utilizamos um índice de produção industrial da Pesquisa Industrial Mensal - Produção Física (PIM-PF) do IBGE. O fator trabalho é representado por uma medida de horas pagas na indústria, ${ }^{9}$ oriunda da Pesquisa Industrial Mensal de Emprego e Salário (PIMES), também

$7 \quad$ King e Rebelo (2000), por exemplo, consideram um modelo com trabalho indivisível (que torna a oferta agregada de trabalho extremamente sensível a mudanças em salários e preços intertemporais, em geral) e com taxas variáveis de utilização da capacidade instalada (que fazem com que a oferta de serviços de capital passe a ser altamente sensível a mudanças no fator trabalho). Além de ressaltar a importância de taxas de utilização da capacidade instalada na explicação de ciclos de negócios, esse modelo utiliza mecanismos de propagação capazes de disseminar os efeitos de choques tecnológicos derivados a partir de medidas corrigidas de produtividade.

8 A principal vantagem de utilizarmos dados industriais neste trabalho reside no fato de que a frequência trimestral é a frequência condizente com ciclos de negócios (COOLEY; PRESCOTT, 1995; STOCK; WATSON 2000).

9 Inicialmente, construímos medidas de PTF em que utilizamos tanto a variável "horas pagas" quanto a variável "pessoal ocupado" para representar o fator trabalho. Como os resultados relacionados a essas medidas foram praticamente idênticos, decidimos reportar apenas resultados nos quais o fator trabalho fosse representado a partir de horas pagas na indústria. 
do IBGE, ao passo que o estoque de capital é representado por estimativas obtidas a partir do método de inventário perpétuo, construídas originalmente por Kanczuk e Faria (2000) e atualizadas pelo autor até o ano de $2001 .{ }^{10}$ Seguindo esses autores, utilizamos um valor de participação do fator capital na renda igual a 0,66.

Uma vez que problemas de mensuração dos fatores de produção podem ser refletidos no resíduo, tornando-o uma medida enviesada de progresso técnico, buscamos capturar uma mensuração mais acurada dos fatores ao considerarmos a importância de taxas de utilização variáveis ao longo do tempo. Uma primeira maneira de fazermos isso é considerarmos o consumo industrial de energia elétrica como uma forma de capturar taxas de utilização variáveis do fator capital na indústria, conforme fizeram Jorgenson e Griliches (1967) e Burnside, Eichenbaum e Rebelo (1995; 1996), por exemplo (medida de produtividade TFPEE). Um problema relacionado a essa alternativa diz respeito à possibilidade de haver uma tendência na série de energia elétrica, o que pode corresponder a um processo de substituição entre máquinas e edificações na indústria.

A segunda maneira de tentarmos captar taxas variáveis de utilização dos fatores equivale ao uso de uma medida corrigida do estoque de capital, como fazem Paquet e Robidoux (2001). No caso, essa correção é feita através do uso de uma medida de utilização da capacidade instalada (UCI) na indústria de bens de capital, elaborada pela Fundação Getúlio Vargas (medida de produtividade TFPUCI). A partir dessas transformações, esperamos captar a importância do uso variável do fator capital em frequências cíclicas. ${ }^{11}$

Seguindo Prescott (1986), utilizamos medidas equivalentes a impulsos de produtividade na análise a seguir. Fazemos isso de modo a obter resultados comparáveis com medidas de produtividade teóricas descritas em modelos RBC. ${ }^{12}$

10 Infelizmente, não foi possível atualizar as estimativas do estoque de capital após 2001, devido ao fato de taxas de investimento para a indústria estarem disponíveis até esse ano, apenas. Em particular, restringimos a análise até o primeiro trimestre de 2001 devido à ocorrência de mudanças metodológicas na construção de algumas variáveis utilizadas na análise, como as taxas de investimento, as horas pagas na indústria e os agregados monetários empregados nos testes de Granger-causalidade expostos a seguir.

11 Decidimos pela escolha da medida de utilização da capacidade instalada da indústria de bens de capital, uma vez que, dentre todas as medidas disponíveis nas bases de dados consultadas, essa parecia refletir de maneira mais acurada o uso variável do fator capital ao longo do tempo. No caso, fazemos uma correção sobre o fator capital nos moldes propostos por Paquet e Robidoux (2001).

12 O Apêndice $\mathrm{C}$ do trabalho detalha a metodologia de construção de impulsos de produtividade e sua relação com testes de Granger-causalidade. 
Na seção de testes de Granger-causalidade, utilizamos variáveis que pudessem captar choques macroeconômicos não relacionados a choques tecnológicos a priori. Assim, para captar os efeitos macroeconômicos da política monetária, utilizamos agregados monetários (conceitos M1, M2 e M3 de moeda), assim como uma medida de taxa de juros (taxa Selic). Devido à ocorrência de períodos inflacionários no país ao longo do período amostral, utilizamos dois índices de preço distintos na análise: o Índice Geral de Preços - Disponibilidade Interna (IGP-DI) e o Índice de Preços ao Consumidor Amplo (IPCA). A partir da inclusão desses índices, esperamos captar os possíveis efeitos da inflação sobre as medidas de produtividade consideradas. Para captar os efeitos macroeconômicos de choques externos, utilizamos três variáveis: o PNB americano e duas medidas de taxas de juros, uma correspondente a uma medida de curto prazo (Federal Funds Rate) e outra correspondente ao longo prazo (10-year bond yield). A fonte desses dados equivale ao Banco Central do Brasil (BACEN).

A Tabela 11, no Apêndice A, contém uma descrição das principais variáveis empregadas na análise descrita a seguir. A maior parte dos dados usados neste trabalho foi obtida a partir do Instituto Brasileiro de Geografia e Estatística (IBGE). ${ }^{13}$

\section{Resultados}

\subsection{Propriedades Estatísticas}

Como primeiro passo de nossa estratégia empírica, realizamos testes de raiz unitária (testes ADF e Phillips-Perron) para todas as variáveis analisadas neste trabalho. Adicionalmente, realizamos o teste KPSS, proposto por Kwiatkowski et al. (1992), como forma de confirmar os diagnósticos obtidos a partir dos testes anteriores. Os resultados desses testes estão contidos no Apêndice A do artigo (Tabelas 12-15). De acordo com esses resultados, podemos notar que a grande maioria das variáveis consideradas pode ser classificada como não estacionárias, com a exceção ficando por conta da taxa de juros americana de longo prazo. Por conta disso, decidimos usar essa última variável expressa em níveis, ao passo que empregamos as demais variáveis sob diferentes representações estacionárias, seja a partir do uso de filtros de diferenças

13 A exceção fica por conta das estimativas do estoque de capital, que foram obtidas a partir da série originalmente construída por Kanczuk e Faria (2000), conforme dito acima. Leitores interessados em obter a base de dados utilizada neste trabalho podem fazê-lo entrando em contato diretamente com o autor. 
(primeiras ou segundas-diferenças, de acordo com a ordem de integração da variável em questão) ou do uso do filtro de Hodrick-Prescott (mais detalhes adiante).

A Tabela 2 apresenta estatísticas descritivas para todas as medidas de produtividade consideradas:

Tabela 2 - Propriedades Estatísticas de Medidas de Produtividades

\begin{tabular}{c|c|c|c}
\hline & TFPSTD & TFPEE & TFPUCI \\
\hline Média & 0,006 & 0,004 & 0,003 \\
\hline Mediana & 0,009 & 0,006 & $-0,003$ \\
\hline Máximo & 0,159 & 0,122 & 0,189 \\
\hline Mínimo & $-0,133$ & $-0,078$ & $-0,159$ \\
\hline Desvio-Padrão & 0,046 & 0,039 & 0,072 \\
\hline Variância Relativa & 0,499 & 0,353 & 1,189 \\
\hline Corr(i, Y) & 0,988 & 0,883 & 0,119 \\
\hline AR(1) & $0,94^{* * *}$ & $0,93 * * *$ & $0,72^{* * *}$ \\
& $(0,05)$ & $(0,06)$ & $(0,09)$ \\
\hline
\end{tabular}

Notas:

(a) Período Amostral: 1985:01/2001:01.

(b) O termo "AR(1)" refere-se às series em níveis, equivalendo ao coeficiente estimado a partir de uma especificação AR(1) (erros-padrão em parênteses).

(c) O símbolo (***) denota rejeição da hipótese nula do teste t ao nível de significância de $1 \%$.

Fonte: Elaborada pelo autor.

A Tabela 2 ressalta as diferenças existentes entre as medidas de produtividade construídas para o período de análise. Por exemplo, as estatísticas relacionadas à variabilidade dessas séries demonstram os efeitos de considerarmos variações nas taxas de utilização do fator capital, uma vez que a medida corrigida pela UCI é a mais cíclica, apresentando, inclusive, uma volatilidade superior a do produto (a estatística "variância relativa" compara a variância de cada medida de produtividade em relação à variância da medida de produção industrial). Por outro lado, a volatilidade da medida TFPEE é inferior à volatilidade do produto, um resultado em consonância com aqueles reportados por Burnside, Eichenbaum e Rebelo (1996) para a economia americana.

Os coeficientes de correlação dessas medidas com a medida de produção industrial ressaltam os impactos de se calcular medidas corrigidas de produtividade. Os valores dessa estatística mudam consideravelmente quando levamos em conta as taxas de utilização dos fatores. No caso, podemos notar que a primeira medida (TFPSTD) apresenta um coeficiente de correlação com a medida de produção industrial em torno 
de 0,99 , o que indica uma associação linear praticamente perfeita com a medida de produto empregada. Quando são feitas correções nessas medidas de produtividade, os coeficientes de correlação tendem a diminuir. A medida TFPEE ainda apresenta um coeficiente relativamente alto, de cerca de 0,88 , um pouco menor do que o coeficiente calculado para a medida anterior. A medida TFPUCI, por outro lado, apresenta um valor para esse coeficiente que demonstra que ela é pouco correlacionada com a medida de produto considerada, no caso de frequências cíclicas (coeficiente de correlação em torno de 0,12). Empiricamente, se choques tecnológicos forem tidos como a principal causa de flutuações na economia, então, pode-se esperar que medidas captando esses choques e medidas de produção agregada seriam bastante correlacionadas, no caso de frequências cíclicas. Entretanto, de acordo com os resultados supracitados, podemos notar que este não é um resultado robusto a diferentes formas de mensuração da produtividade. ${ }^{14}$

Relacionados a esse último ponto são os resultados contidos na Tabela 3, que apresenta as correlações entre as principais variáveis empregadas ao longo da análise. No caso dessa tabela, os termos $y, h$, $e e, k$ e $k$ (corr) representam, respectivamente, as variáveis produto (industrial), horas, consumo industrial de energia elétrica, estoque de capital e estoque de capital corrigido via UCI.

Tabela 3 - Correlações entre Produção, Insumos e Medidas de Produtividade

\begin{tabular}{c|c|c|c|c|c|c|c|c}
\hline & & & & & (b) & & & \\
\hline & $\Delta \mathrm{y}_{\mathrm{t}}$ & $\Delta \mathrm{h}_{\mathrm{t}}$ & $\Delta \mathrm{e}_{\mathrm{t}}$ & $\Delta \mathrm{k}_{\mathrm{t}}$ & $\begin{array}{c}\Delta \mathrm{k}_{\mathrm{t}} \\
(\text { corr })\end{array}$ & $\Delta$ (TFPSTD) & $\Delta$ (TFPEE) & $\Delta$ (TFPUCI) \\
\hline$\Delta \mathrm{y}_{\mathrm{t}}$ & 1,00 & & & & & & & \\
\hline$\Delta \mathrm{h}_{\mathrm{t}}$ & 0,66 & 1,00 & & & & & & \\
\hline$\Delta \mathrm{e}_{\mathrm{t}}$ & 0,59 & 0,53 & 1,00 & & & & & \\
\hline$\Delta \mathrm{k}_{\mathrm{t}}$ & $-0,09$ & 0,42 & 0,24 & 1,00 & & & & \\
\hline$\Delta \mathrm{k}_{\mathrm{t}}(\mathrm{corr})$ & 0,48 & 0,40 & 0,53 & 0,04 & 1,00 & & & \\
\hline$\Delta($ TFPSTD $)$ & 0,99 & 0,54 & 0,55 & $-0,18$ & 0,46 & 1,00 & & \\
\hline$\Delta($ TFPEE $)$ & 0,88 & 0,38 & 0,16 & $-0,33$ & 0,28 & 0,91 & 1,00 & \\
\hline$\Delta($ TFPUCI $)$ & 0,10 & $-0,09$ & $-0,23$ & $-0,15$ & $-0,82$ & 0,13 & 0,27 & 1,00 \\
\hline & & & & \multicolumn{7}{|c|}{} & & & & \\
\hline
\end{tabular}

(continua)

14 Na verdade, este é um resultado condizente com uma das regularidades empíricas dos ciclos de negócios, qual seja o fato de as medidas de produtividade e produto serem pouco correlacionadas no caso de altas frequências. Devido à inconsistência entre as previsões teóricas advindas de modelos RBC e essa regularidade empírica, alguns autores denominam esse fato de "enigma da produtividade" (STADLER, 1994, p. 1757). 


\begin{tabular}{c|c|c|c|c|c|c|c|c}
\hline & $\mathrm{y}_{\mathrm{t}}$ & $\mathrm{h}_{\mathrm{t}}$ & $\mathrm{ee}_{\mathrm{t}}$ & $\mathrm{k}_{\mathrm{t}}$ & $\mathrm{k}_{\mathrm{t}}$ (corr) & TFPSTD & TFPEE & TFPUCI \\
\hline $\mathrm{y}_{\mathrm{t}}$ & 1,00 & & & & & & & \\
\hline $\mathrm{h}_{\mathrm{t}}$ & 0,79 & 1,00 & & & & & & \\
\hline $\mathrm{ee}_{\mathrm{t}}$ & 0,61 & 0,50 & 1,00 & & & & & \\
\hline $\mathrm{k}_{\mathrm{t}}$ & $-0,21$ & $-0,08$ & $-0,10$ & 1,00 & & & & \\
\hline $\mathrm{k}_{\mathrm{t}}$ (corr) & 0,58 & 0,51 & 0,57 & $-0,07$ & 1,00 & & & \\
\hline TFPSTD & 0,97 & 0,64 & 0,59 & $-0,30$ & 0,55 & 1,00 & & \\
\hline TFPEE & 0,86 & 0,51 & 0,18 & $-0,24$ & 0,36 & 0,90 & 1,00 & \\
\hline TFPUCI & 0,12 & $-0,07$ & $-0,18$ & $-0,12$ & $-0,72$ & 0,18 & 0,32 & 1,00 \\
\hline NOTAS: & & & & & & &
\end{tabular}

Notas:

(a) Período Amostral: 1985:01/2001:01.

(b) Dados expressos como primeiras-diferenças dos logaritmos naturais.

(c) Dados expressos como componentes cíclicos das séries consideradas, obtidos a partir do filtro de Hodrick-Prescott $(\lambda=1600)$.

Fonte: Elaborada pelo autor.

De acordo com as correlações reportadas na Tabela 3, podemos notar alguns fatos básicos. Primeiro, a medida de horas pagas na indústria é altamente correlacionada com a medida de produção industrial, com os coeficientes de correlação entre essas variáveis sendo de 0,66 e 0,79, para dados em primeiras-diferenças e dados filtrados através do procedimento proposto por Hodrick e Prescott (1997), respectivamente. Segundo, o consumo industrial de energia elétrica apresenta uma correlação com a medida de produto de cerca de $0,59(0,61$, para dados filtrados via Hodrick-Prescott), enquanto que, quando consideramos a medida de capital, essa correlação cai para -0,09 (-0,21). Burnside, Eichenbaum e Rebelo (1995) obtêm um resultado semelhante para a economia americana em nível agregado, embora as magnitudes reportadas por esses autores sejam superiores às nossas. De qualquer forma, em ambos os casos, podemos notar que as taxas de variação do estoque de capital e do produto industrial são praticamente não correlacionadas em frequências cíclicas, o que está de acordo com os fatos estilizados relacionados a ciclos de negócios (COOLEY; PRESCOTT, 1995). Terceiro, as taxas de variação da medida corrigida de capital apresentam valores superiores para os coeficientes de correlação com a produção industrial, de cerca de $0,48(0,58)$, o que provavelmente deve-se à correção feita sobre o fator capital para que esse fator passe a incorporar taxas variáveis de utilização da capacidade instalada.

Em termos de taxas de variação e componentes cíclicos das medidas de produtividade consideradas, podemos notar novamente que a medida TFPSTD é a mais correlacionada com a produção industrial 
(coeficientes de correlação entre 0,97 e 0,99), ao passo que as medidas corrigidas (TFPEE e TFPUCI) são menos correlacionadas. Vale a pena notar que a situação é a mesma em termos dos coeficientes de correlação das medidas de produtividade com a medida de horas pagas. Em particular, apenas a medida TFPUCI é negativamente correlacionada com a medida de horas pagas na indústria.

Outra medida interessante a ser considerada aqui é o coeficiente que mede a persistência dessas medidas de produtividade (ver Tabela 2). Em geral, modelos RBC empregam duas formas básicas de representar choques tecnológicos: ou como processos AR(1) com alta persistência (um valor de $\rho$ próximo a um, sendo, em geral, fixado arbitrariamente em 0,95$)$ ou como processos random-walk $(\rho=1)$. Ao contrário das demais estatísticas descritas, esta é uma estatística calculada para as séries em níveis (simplesmente estima-se um AR(1) para cada série original de produtividade). Para cada coeficiente $\rho$ estimado, é reportado adicionalmente o erro-padrão das estimativas. Pelos resultados obtidos, podemos notar que os coeficientes estimados variam de acordo com a medida de produtividade considerada. Assim, ao passo que as duas primeiras medidas exibem valores em torno de 0,94 , a medida corrigida pela UCI apresenta um valor menor, em torno de 0,72 (com este valor sendo significativo ao nível de $1 \%) .{ }^{15}$

\subsection{Testes de Granger-Causalidade}

Seguindo Hall (1988; 1990) e Evans (1992), expomos nesta parte os resultados de testes de Granger-causalidade relacionados às medidas de produtividade consideradas e a variáveis macroeconômicas que buscam captar os efeitos de outros choques na economia.

As Tabelas 4 e 5 contêm resultados relacionados a esses testes para as medidas de produtividade consideradas. No caso, consideramos variáveis macroeconômicas que a priori não estariam relacionadas com medidas de produtividade: os agregados monetários M1, M2 e M3, a taxa de juros Selic, os índices de preço IGP-DI e IPCA e três medidas relacionadas ao setor externo da economia, o PNB americano e duas taxas de juros (uma de curto e outra de longo prazo). A Tabela 4 contém resultados para testes de Granger-causalidade bivariados, ao passo que a Tabela 5 contém resultados para testes multivariados de bloco-exogeneidade.

15 Ver, a esse respeito, Hansen (1997), que demonstra a importância da forma de modelagem do choque tecnológico em modelos $\mathrm{RBC}$ e as principais consequências daí advindas. Em particular, esse autor demonstra que mudanças no processo estocástico seguido por choques de produtividade em modelos RBC alteram significativamente os resultados desses modelos. 
Tabela 4 - Testes de Granger-Causalidade Bivariados

\begin{tabular}{c|c|c|c|c|c|c|c|c|c}
\hline \multicolumn{7}{c}{ Primeiras-Diferenças dos Logaritmos Naturais } \\
\hline & M1 & M2 & M3 & Selic & IGP-DI & IPCA & $\begin{array}{c}\text { U.S. } \\
\text { GDP }\end{array}$ & $\begin{array}{c}\text { U.S. } \\
\text { Fed. } \\
\text { Funds } \\
\text { Rate }\end{array}$ & $\begin{array}{c}\text { U.S. } \\
\text { Long } \\
\text { Term } \\
\text { Rate }\end{array}$ \\
\hline TFPSTD & $0,051^{*}$ & $0,037^{* *}$ & $0,001^{* * *}$ & $0,001^{* * *}$ & $0,023^{* *}$ & $0,009^{* * *}$ & 0,257 & 0,434 & 0,988 \\
\hline TFPEE & 0,27 & 0,105 & $0,004^{* * *}$ & $0,01^{* *}$ & $0,04^{* *}$ & $0,072^{*}$ & 0,161 & 0,525 & 0,922 \\
\hline TFPUCI & 0,356 & 0,391 & 0,602 & 0,41 & 0,304 & 0,356 & 0,522 & 0,982 & 0,596 \\
\hline
\end{tabular}

Notas:

(a) Período Amostral: 1985:01/2001:01.

(b) O número de defasagens usado em cada teste foi fixado em quatro.

(c) A tabela reporta os p-valores associados à hipótese nula de cada teste.

(d) Os símbolos $\left({ }^{*}\right),\left({ }^{* *}\right)$ e $(* * *)$ denotam rejeição da hipótese nula de cada teste (" $x$ não Granger-causa $\left.y^{\prime \prime}\right)$ aos níveis de significância de 10\%, 5\% e 1\%, respectivamente.

Fonte: Elaborada pelo autor.

De acordo com os resultados contidos na Tabela 4, podemos notar que a única medida de produtividade que obedece à propriedade de invariância de Hall-Evans, no contexto do setor industrial brasileiro, é a medida de produtividade total dos fatores em que o fator capital é corrigido pela utilização da capacidade instalada (TFPUCI). No caso, podemos observar que esta medida não é Granger-causada por nenhuma das demais medidas macroeconômicas empregadas na análise. Por outro lado, medidas de produtividade construídas de acordo com a metodologia convencional ou de acordo com uma metodologia na qual taxas variáveis de utilização dos fatores sejam aproximadas a partir do consumo industrial de energia elétrica são Granger-causadas pela maior parte das variáveis macroeconômicas em questão. Um ponto interessante a ser destacado diz respeito ao fato de nenhuma das medidas de produtividade empregadas na análise ser Granger-causada por medidas que representam o setor externo da economia.

No caso dos testes multivariados, estimamos especificações multivariadas (VARs, basicamente) envolvendo medidas de produtividade e diversas combinações de outras variáveis macroeconômicas, denominadas "blocos", na Tabela 5. As variáveis dependentes nessas especificações equivalem a vetores contendo valores correntes e defasados de medidas de produtividade. Os blocos considerados foram os seguintes: 
a) "Bloco Monetário": composto pelo agregado monetário M2, pela taxa de juros Selic e pelo índice de preços IGP-DI. ${ }^{16}$

b) "Bloco Monetário (sem inflação)": composto pelas variáveis anteriores, exceto o índice de preços.

c) "Bloco Externo": composto pelo PNB e pelas taxas de juros americanas de curto e longo prazo.

d) "Bloco Total": composto por todas as variáveis listadas nos itens anteriores.

Um fato conhecido da estimação de VARs é que a inclusão de novas variáveis na estimação pode fazer com que se percam graus de liberdade rapidamente, com isso sendo verdadeiro especialmente no caso do último bloco, que inclui todas as variáveis. Assim, os resultados relacionados a esse último bloco devem ser vistos com cautela, servindo apenas para fornecer maior grau de robustez aos resultados de testes bivariados.

Tabela 5 - Testes de Granger-Causalidade Multivariados

\begin{tabular}{c|c|c|c|c}
\hline Medida & Bloco Total & Bloco Monetário & $\begin{array}{c}\text { Bloco Monetário } \\
\text { (sem inflação) }\end{array}$ & $\begin{array}{c}\text { Bloco } \\
\text { Externo }\end{array}$ \\
\hline \multicolumn{5}{c}{ Primeiras-Diferenças dos Logaritmos Naturais } \\
\hline TFPSTD & $0,007^{* * *}$ & $0,001^{* * *}$ & $0,000^{* * *}$ & 0,629 \\
\hline TFPEE & $0,031^{* *}$ & $0,016^{* *}$ & $0,01^{* * *}$ & 0,646 \\
\hline TFPUCI & 0,999 & 0,895 & 0,63 & 0,887 \\
\hline
\end{tabular}

Notas:

(a) Os testes conduzidos correspondem a testes de Bloco-Exogeneidade envolvendo as variáveis em questão.

(b) O número de defasagens usado em cada teste foi fixado em quatro.

(c) A tabela reporta os p-valores associados à hipótese nula de cada teste.

(d) Blocos: "Monetário" (M2, taxa de juros Selic e índice IGP-DI); "Monetário (sem inflação)": (M2 e Selic); "Externo" (PNB-EUA e taxas de juros norte-americanas); "Total" (todas as variáveis empregadas nos testes bivariados).

(e) Período Amostral: 1985:01/2001:01.

(f) Os símbolos $\left(^{*}\right),\left({ }^{* *}\right)$ e ${ }^{* * *}$ ) denotam rejeição da hipótese nula de cada teste (" $x$ não Granger-causa y") aos níveis de significância de 10\%, 5\% e 1\%, respectivamente.

Fonte: Elaborada pelo autor.

Os resultados dos testes multivariados reforçam os resultados dos testes bivariados. Mais uma vez, é possível constatar que todas as medidas de produtividade consideradas não são Granger-causadas pelas

16 Os resultados dos testes multivariados não mudam caso consideremos o índice IPCA no lugar do IGP-DI, ou os agregados monetários M1 ou M3 no lugar de M2. Com o intuito de poupar espaço, decidimos reportar apenas os resultados relacionados a estimações contendo $\mathrm{o}$ índice de preços IGP-DI e o agregado monetário M2. 
medidas que buscam captar choques externos na economia. Por outro lado, os demais blocos Granger-causam as medidas TFPSTD e TFPEE, conforme já ocorria no caso bivariado. No caso multivariado, a medida TFPUCI é a única medida de produtividade que não é Granger-causada por nenhum dos blocos em questão.

Em suma, os resultados apresentados nesta seção chamam atenção para a importância da metodologia empregada na construção de medidas de produtividade. Medidas que não levam em conta a importância de taxas de utilização dos fatores variáveis ao longo do tempo apresentam propriedades estatísticas nitidamente distintas de medidas que incorporam tais modificações.

\section{Testes de Robustez}

Nesta seção reportamos os resultados de testes realizados para checarmos a robustez dos principais resultados obtidos. Basicamente, conduzimos dois testes de robustez distintos: um no qual modificamos o método de filtragem das séries utilizadas neste trabalho e outro em que alteramos o número de defasagens empregadas nos testes de Grangercausalidade.

\subsection{Métodos de Filtragem Empregados}

No caso do primeiro teste de robustez, sua execução pode ser justificada a partir do fato de que alguns autores concluíram que resultados empíricos relacionados a modelos de ciclos de negócios podem ser afetados pelo método de filtragem utilizado para estacionarizar as séries em questão (COGLEY; NASON, 1995; TELES et al., 2005). Por conta disso, refizemos a análise apresentada anteriormente utilizando séries que foram estacionarizadas a partir de dois métodos distintos: em um caso, utilizamos as primeiras e segundas-diferenças das séries em questão, ${ }^{17}$ enquanto que em outro caso utilizamos os componentes cíclicos de cada série obtidos a partir do uso do filtro de Hodrick-Prescott. ${ }^{18}$ Os resultados para esses testes são reportados nas Tabelas 6, 7 e 8. A Tabela 6 contém resultados relacionados às propriedades estatísticas das medidas de produtividade consideradas, ao passo que as Tabelas 7 e 8 apresentam os resultados de testes de Granger-causalidade para os casos bivariado e multivariado, respectivamente.

17 O uso de séries em primeiras ou segundas-diferenças deve-se à ordem de integração de cada variável considerada.

18 Vale ressaltar que também foram realizados testes com variáveis filtradas a partir do método Band Pass (BAXTER; KING, 1999). Os resultados desses testes (não reportados) são qualitativamente similares aos resultados obtidos a partir do filtro Hodrick-Prescott. 
Tabela 6 - Robustez: Propriedades Estatísticas de Medidas de PTF para Diferentes Transformações dos Dados

\begin{tabular}{c|c|c|c}
\hline \multicolumn{5}{c}{ Impulsos de Produtividade ${ }^{\mathbf{b}}$} \\
\hline Média & TFPSTD & TFPEE & TFPUCI \\
\hline Mediana & $1,70 \mathrm{E}-15$ & $3,99 \mathrm{E}-15$ & $2,61 \mathrm{E}-14$ \\
\hline Máximo & 0,006 & 0,005 & $-0,004$ \\
\hline Mínimo & 0,142 & 0,108 & 0,191 \\
\hline Desv.Pad. & $-0,143$ & $-0,083$ & $-0,126$ \\
\hline Var.Relat. & 0,046 & 0,039 & 0,067 \\
\hline Corr(i, Y) & 0,811 & 0,569 & 1,707 \\
\hline & 0,982 & 0,882 & 0,181 \\
\hline & Dados filtrados via Hodrick-Prescott & \\
\hline Média & TFPSTD & TFPEE & TFPUCI \\
\hline Mediana & $-3,55 \mathrm{E}-13$ & $-2,61 \mathrm{E}-13$ & $-2,41 \mathrm{E}-13$ \\
\hline Máximo & $5,73 \mathrm{E}-05$ & $5,48 \mathrm{E}-06$ & $-1,29 \mathrm{E}-05$ \\
\hline Mínimo & 0,0010 & 0,0009 & 0,0011 \\
\hline Desv.Pad. & $-0,0013$ & $-0,0007$ & $-0,0009$ \\
\hline Var.Relat. & 0,0004 & 0,0003 & 0,0005 \\
\hline Corr(i, Y) & 0,0001 & 0,00004 & 0,0001 \\
\hline Notas & 0,974 & 0,859 & 0,124 \\
\hline
\end{tabular}

Notas:

(a) Período Amostral: 1985:01/2001:01.

(b) Dados expressos como resíduos de regressões envolvendo medidas de produtividade em que cada medida foi regredida em uma constante e em um valor defasado um período.

(c) Dados expressos como componentes cíclicos das séries consideradas, obtidos a partir do filtro de Hodrick-Prescott $(\lambda=1600)$.

Fonte: Elaborada pelo autor.

Tabela 7 - Robustez: Testes de Granger-Causalidade Bivariados para Diferentes Transformações dos Dados

\begin{tabular}{c|c|c|c|c|c|c|c|c|c}
\hline M1 & M2 & M3 & Selic & IGP-DI & IPCA & $\begin{array}{c}\text { U.S. } \\
\text { GDP }\end{array}$ & $\begin{array}{c}\text { U.S. } \\
\text { Fund. } \\
\text { Funds } \\
\text { Rate }\end{array}$ & $\begin{array}{c}\text { U.S. } \\
\text { Long } \\
\text { Term } \\
\text { Rate }\end{array}$ \\
\hline
\end{tabular}

\begin{tabular}{c|c|c|c|c|c|c|c|c|c}
\hline \multicolumn{10}{c}{ Impulsos de Produtividade } \\
\hline TFPSTD & $0,026^{* *}$ & $0,014^{* *}$ & $0,000^{* * *}$ & $0,000^{* * *}$ & $0,018^{* *}$ & $0,007^{* * *}$ & 0,215 & 0,449 & 0,97 \\
\hline TFPEE & 0,206 & $0,048^{* *}$ & 0,001 & $0,007^{* * *}$ & $0,032^{* *}$ & $0,061^{*}$ & 0,107 & 0,57 & 0,954 \\
\hline TFPUCI & 0,419 & 0,33 & 0,593 & 0,454 & 0,47 & 0,492 & 0,599 & 0,897 & 0,764 \\
\hline
\end{tabular}




\begin{tabular}{c|c|c|c|c|c|c|c|c|c}
\hline \multicolumn{1}{c}{ Dados filtrados via Hodrick-Prescott } \\
\hline TFPSTD & $0,034^{* *}$ & $0,044^{* *}$ & $0,001^{* * *}$ & $0,000^{* * *}$ & $0,026^{* *}$ & $0,011^{* *}$ & 0,421 & 0,224 & 0,9 \\
\hline TFPEE & $0,097^{*}$ & $0,06^{*}$ & $0,002^{* * *}$ & $0,006^{* * *}$ & $0,041^{* *}$ & $0,059^{*}$ & 0,334 & 0,196 & 0,584 \\
\hline TFPUCI & $0,07^{*}$ & 0,257 & 0,316 & 0,406 & 0,337 & 0,332 & 0,786 & 0,952 & 0,41 \\
\hline
\end{tabular}

Nota: ver Tabela 4.

Fonte: Elaborada pelo autor.

Tabela 8 - Robustez: Testes de Granger-Causalidade Multivariados para Diferentes Transformações dos Dados

\begin{tabular}{c|c|c|c|c}
\hline Medida & Bloco Total & Bloco Monetário & $\begin{array}{c}\text { Bloco Monetário } \\
\text { (sem inflação) }\end{array}$ & Bloco Externo \\
\hline \multicolumn{5}{c}{ Impulsos de Produtividade } \\
\hline TFPSTD & $0,004^{* * *}$ & $0,000^{* * *}$ & $0,000^{* * *}$ & 0,637 \\
\hline TFPEE & $0,02^{* *}$ & $0,005^{* * *}$ & $0,002^{* * *}$ & 0,653 \\
\hline TFPUCI & 0,999 & 0,917 & 0,583 & 0,918 \\
\hline \multicolumn{5}{c}{ Dados filtrados via Hodrick-Prescott } \\
\hline TFPSTD & $0,000^{* * *}$ & $0,001^{* * *}$ & $0,015^{* *}$ & 0,362 \\
\hline TFPEE & $0,000^{* * *}$ & $0,006^{* * *}$ & $0,028^{* *}$ & 0,105 \\
\hline TFPUCI & 0,926 & 0,875 & 0,645 & 0,738 \\
\hline
\end{tabular}

Nota: ver Tabela 5.

Fonte: Elaborada pelo autor.

Conforme pode ser visto a partir de uma inspeção dos dados contidos nessas tabelas, os resultados obtidos não são alterados nesse caso. Especificamente, temos que a medida de produtividade TFPUCI apresenta propriedades estatísticas nitidamente distintas das demais medidas de produtividade, sendo mais volátil do que ambas, ao mesmo tempo em que é menos correlacionada com a medida de produção industrial. Em termos dos resultados de testes de Granger-causalidade, podemos observar que apenas a medida TFPUCI não é Granger-causada pelas demais variáveis macroeconômicas consideradas, independentemente da transformação estacionária ou do tipo de teste considerado (teste bivariado ou multivariado).

5.2 Número de Defasagens Empregado em Testes de GrangerCausalidade

No caso deste teste de robustez, dada a conhecida sensibilidade de testes de Granger-causalidade ao número de defasagens empregado, 
refazemos esses testes para a medida TFPUCI com números alternativos de defasagens ( 1 ou 2 defasagens, no caso). Do mesmo modo, seguindo a lógica do primeiro teste de robustez descrito, utilizamos diferentes métodos de filtragem dos dados ao refazermos os testes de Grangercausalidade. Os resultados desse teste de robustez estão contidos nas Tabelas 9 e 10.

Tabela 9 - Robustez: Testes Bivariados de Granger-Causalidade para a medida de Produtividade TFPUCI com Números Alternativos de Defasagens

\begin{tabular}{c|c|c|c|c|c|c|c|c|c|c}
\hline & Defs. & M1 & M2 & M3 & Selic & $\begin{array}{c}\text { IGP- } \\
\text { DI }\end{array}$ & IPCA & $\begin{array}{c}\text { U.S. } \\
\text { GDP }\end{array}$ & $\begin{array}{c}\text { U.S. } \\
\text { Fund. } \\
\text { Funds } \\
\text { Rate }\end{array}$ & $\begin{array}{c}\text { U.S. } \\
\text { Long } \\
\text { Term } \\
\text { Rate }\end{array}$ \\
\hline \multirow{2}{*}{ Impulsos } & 1 & 0,75 & 0,212 & 0,207 & 0,924 & 0,816 & 0,806 & $0,053^{*}$ & 0,594 & 0,763 \\
\cline { 2 - 11 } & 2 & 0,243 & 0,242 & 0,248 & 0,942 & 0,983 & 0,97 & 0,123 & 0,913 & 0,541 \\
\hline $\begin{array}{c}\text { Primei- } \\
\text { ras-Dife- } \\
\text { renças }\end{array}$ & 1 & 0,194 & 0,54 & 0,541 & 0,86 & 0,862 & 0,903 & 0,122 & 0,198 & 0,899 \\
\hline \multirow{2}{*}{ H-P } & 1 & 0,457 & 0,606 & 0,662 & 0,887 & 0,922 & 0,985 & 0,169 & 0,687 & 0,19 \\
\cline { 2 - 11 } & 2 & $0,066 *$ & 0,182 & 0,225 & 0,593 & 0,183 & 0,174 & 0,234 & 0,762 & 0,3 \\
\hline
\end{tabular}

Nota: ver Tabela 4.

Fonte: Elaborada pelo autor.

Tabela 10 - Robustez: Testes Multivariados de Granger-Causalidade para a medida de Produtividade TFPUCI com Números Alternativos de Defasagens

\begin{tabular}{c|c|c|c|c|c}
\hline & Defs. & Bloco Total & $\begin{array}{c}\text { Bloco Mone- } \\
\text { tário }\end{array}$ & $\begin{array}{c}\text { Bloco } \\
\text { Monetário } \\
\text { (sem inflação) }\end{array}$ & Bloco Externo \\
\hline \multirow{2}{*}{ Impulsos } & 1 & 0,259 & 0,658 & 0,451 & 0,199 \\
\cline { 2 - 6 } & 2 & 0,295 & 0,549 & 0,368 & 0,361 \\
\hline \multirow{2}{*}{$\begin{array}{c}\text { Primei- } \\
\text { ras-Dife- } \\
\text { renças }\end{array}$} & 1 & 0,434 & 0,853 & 0,825 & 0,175 \\
\cline { 2 - 6 } & 2 & 0,478 & 0,8 & 0,56 & 0,333 \\
\hline \multirow{2}{*}{ H-P } & 1 & 0,824 & 0,664 & 0,532 & 0,87 \\
\cline { 2 - 6 } & 2 & 0,495 & 0,744 & 0,482 & 0,353 \\
\hline
\end{tabular}

Nota: ver Tabela 5.

Fonte: Elaborada pelo autor.

Podemos constatar que os resultados obtidos anteriormente também são robustos ao uso de diferentes números de defasagens em testes de Granger-causalidade. Em particular, não é possível rejeitarmos as 
hipóteses nulas dos testes de Granger-causalidade bivariado e multivariado ao nível de significância de $5 \%$ para todas as tranformações estacionárias da medida de produtividade TFPUCI.

\section{Considerações Finais e Agenda de Pesquisa Futura}

Neste trabalho tentamos responder à seguinte pergunta: variações na metodologia de cálculo de medidas de produtividade podem gerar resíduos de Solow com propriedades estatísticas distintas? No caso de dados industriais brasileiros analisados ao longo do período 1985:01/2001:01, nossos resultados demonstram que, em termos empíricos, existem diferenças consideráveis entre medidas calculadas a partir de metodologias distintas. Além disso, obtemos um resultado no qual apenas a medida de produtividade que incorpora taxas variáveis de utilização da capacidade instalada obedece à propriedade de invariância de Hall-Evans. Os resultados obtidos são robustos a variações nos métodos de filtragem das séries empregadas neste estudo, bem como as modificações no número de defasagens empregado em testes de Granger-causalidade. Esses resultados reforçam a importância da mensuração do resíduo de Solow no caso de horizontes correspondentes a ciclos de negócios.

Em termos de pesquisa futura, sugerimos duas possibilidades. Uma possibilidade teórica seria a calibração de modelos teóricos que incorporassem choques tecnológicos originados a partir de medidas de produtividade que considerassem taxas variáveis de utilização dos fatores, nos moldes propostos por Bils e Cho (1994) e Cooley, Hansen e Precott (1995), por exemplo. Por outro lado, uma possibilidade empírica seria um estudo com objetivos semelhantes a este, mas que utilizasse dados em painel, na mesma linha seguida por Burnside, Eichenbaum e Rebelo (1995), por exemplo. Uma vantagem do uso de dados em painel, ao invés de séries temporais, seria que dados desse tipo apresentam, em geral, um maior grau de heterogeneidade individual, um fato que poderia garantir maior robustez aos resultados aqui descritos.

\section{Referências}

BANCO CENTRAL DO BRASIL. Boletim (Seção Moeda e Crédito). 2004. Disponível em http://www.bcb.gov.br/. Acesso em 16 fev. 2004.

BASU, S.; FERNALD, J. G.; KIMBALL, M. Are technology improvements contractionary?. International Finance Discussion Paper Series: Board of Governors of the Federal Reserve System, n. 625, p. 1-56, sep. 1998. 
BAXTER, M.; KING, R. G. Measuring business cycles: approximate band-pass filters for economic time series. Review of Economics and Statistics, v. 81, n. 4, p. 575-593, nov. 1999.

BILS, M.; CHO, J. Cyclical factor utilization. Journal of Monetary Economics, v. 33, n. 3, p. 319-354, 1994.

BURNSIDE, C.; EICHENBAUM, M. Factor-hoarding and the propagation of businesscycle shocks. American Economic Review, v. 86, n. 5, p. 1154-1174, 1996.

BURNSIDE, C.; EICHENBAUM, M.; REBELO, S. Capital utilization and returns to scale. NBER Macroeconomics Annual, p. 67-110, 1995. apr. 1996.

Sectoral Solow residuals. European Economic Review, v. 40, n. 4, p. 861-869,

COGLEY, T.; NASON, J. M. Effects of the Hodrick-Prescott filter on trend and difference stationary time series: implications for business cycle research. Journal of Economic Dynamics and Control, v. 19, n. 2, p. 253-278, 1995.

COOLEY, T. F. (Ed.). Frontiers of business cycle research. New Jersey: Princeton University, 1995.

COOLEY, T. F.; PRESCOTT, E. C. Economic growth and business cycles. In: COOLEY, T. F. (Ed.) Frontiers of business cycle research. New Jersey: Princeton University, p. 1-38, 1995.

COOLEY, T. F.; HANSEN, G. D.; PRESCOTT, E. C. Equilibrium business cycles with idle resources and variable capacity utilization. Economic Theory, v. 6, n. 1, p. 35-49, 1995.

DICKEY, D. A.; FULLER, W. A. Likelihood ratio statistics for autoregressive time series with a unit root. Econometrica, v. 49, n. 4, p. 1057-1073, 1981.

ELETROBRAS. Consumo industrial de energia elétrica. Boletim SIESE. 2004. Disponível em http://www.eletrobras.com/elb/data.htm. Acesso em 16 fev. 2004.

EVANS, C. I. Productivity shocks and real business cycles. Journal of Monetary Economics, v. 29, n. 2, p. 191-208, apr. 1992.

FUNDAÇÃO GETÚLIO VARGAS. Índice de utilização da capacidade instalada. 2004. Disponível em http://portal.fgv.br/. Acesso em 16 fev. 2004.

GRILICHES, Z. The discovery of the residual: a historical note. Journal of Economic Literature, v. 34, n. 1, p. 1324-1330, sept. 1996.

HALL, R. E. Invariance properties of Solow's productivity residual. In: DIAMOND, P. (Ed.). Growth/productivity/unemployment: essays in honour of Bob Solow's $70^{\text {th }}$ birthday, p. 71-112, Cambridge: MIT, 1990.

. The relation between price and marginal cost in U.S. industry. Journal of Political Economy, v. 96, n. 5, p. 921-947, 1988.

HANSEN, G. D. What is real business cycle theory? Jobs and Capital (Milken Institute for Job and Capital Formation), v. 3, p. 7-10, 1994.

. Technical progress and aggregate fluctuations. Journal of Economic Dynamics and Control, v. 21, n. 4, p. 1005-1023, 1997.

HODRICK, R.; PRESCOTT, E. C. Post-war U.S. business cycles: a descriptive empirical investigation. Journal of Money, Credit and Banking, v. 29, n. 1, p. 1-16, 1997. 
INSTITUTO BRASILEIRO DE GEOGRAFIA E ESTATÍSTICA. Pesquisa industrial mensal: produção física (PIM-PF). 2004. Disponível em http://www.sidra.ibge.gov.br/bda/acervo/ acervo2 $\cdot \operatorname{asp} ? \mathrm{ti}=1 \mathcal{E} \mathrm{tf}=99999 \mathcal{E} \mathrm{E}=\mathrm{c} \mathcal{E} \mathrm{p}=\mathrm{PZE} \mathcal{E} \mathrm{v}=28 \mathcal{E} \mathrm{Z}=\mathrm{t} \mathcal{E} \mathrm{O}=21$. Acesso em 12 fev. 2004 .

. Pesquisa industrial mensal de emprego e salário (PIMES). 2004. Disponível em $\overline{\mathrm{http}} / / / \mathrm{w} w w$. sidra.ibge.gov.br/bda/acervo/acervo2 $\cdot \mathrm{asp} ? \mathrm{ti}=1 \mathcal{E} \mathrm{tf}=99999 \mathcal{E} \mathrm{e}=\mathrm{c} \mathcal{E} \mathrm{p}=\mathrm{XY} \mathcal{E} \mathrm{V}$ $=685 \mathcal{E} \mathrm{Z}=\mathrm{t} \mathcal{E} \mathrm{O}=21$. Acesso em 12 fev. 2004.

JORGENSON, D. W.; GRILICHES, Z. The explanation of productivity change. Review of Economic Studies, v. 34, n. 3, p. 249-283, jun. 1967.

KANCZUK, F.; FARIA, F, J. Ciclos reais para a indústria brasileira? Estudos Econômicos, V. 47, n. 4, p. 335-350, 2000.

KING, R. G.; REBELO, S. Ressuscitating real business cycles. In: TAYLOR, J.; WOODFORD, M. (Ed.). Handbook of Macroeconomics, North-Holland, p. 927-1007, 2000.

KYDLAND, F.; PRESCOTT, E. C. Time to build and aggregate fluctuations. Econometrica, v. 50, n. 6, p. 1345-1370, 1982.

KWIATKOWSKI, D. et al. Testing the nll hypothesis of stationarity against the alternative of unit root. Journal of Econometrics, v. 54, n. 1, p. 159-178, 1992.

LONG, J. B.; PLOSSER, C. I. Real business cycles. Journal of Political Economy, v. 9, n. 1, p. 39-69, 1983.

MACKINNON, J. G. Critical values for cointegration tests. In: ENGLE, R. F.; GRANGER, C. W. J. (Ed.) Long-run economic relationships: readings in cointegration. Oxford University, 1991.

MAGALHÃES, M. A. Equilíbrio e ciclos. Revista de Economia Contemporânea, v. 9, n. 3 , p. 509-554, set.-dez. 2005.

MIDRIGAN, V. Is firm pricing state or time-dependent? Evidence from US manufacturing. Review of Economics and Statistics, v. 92, n. 3, p. 643-656, aug. 2010.

OTTO, G. The Solow residual for Australia: technology shocks or factor utilization? Economic Inquiry, v. 37, n. 1, p. 136-153, jan. 1999.

PAQUET, A.; ROBIDOUX, B. Issues on the measurement of the Solow residual and the testing of its exogeneity: evidence for Canada. Journal of Monetary Economics, v. 47, n. 3, p. 595-612, 2001.

PHILLIPS, P. C. B.; PERRON, P. Testing for unit roots in time series regression. Biometrika, V. 75, n. 3, p. 335-346, 1988.

PRESCOTT, E. C. Theory ahead of business cycle measurement. Federal Reserve Bank of Minneapolis Quarterly Review, v. 10, n. 4, p. 9-22, fall 1986.

REBELO, S. Real Business Cycle models: past, present and future. Northwestern University, mimeo., Mar. 2005, 25p.

SOLOW, R. M. A contribution to the theory of economic growth. Quarterly Journal of Economics, v. 70, n. 1, p. 65-94, feb. 1956.

. Technical change and the aggregate production function. The Review of Economics and Statistics, v. 39, n. 3, p. 312-320, aug. 1957.

STADLER, G. W. Real business cycles. Journal of Economic Literature, v. 32, n. 4, p. 1750-1783, Dec. 1994. 
STOCK, J. H.; WATSON, M. W. Business cycle fluctuations in U.S. macroeconomic time series. In: TAYLOR, J.; WOODFORD, M. (Ed.) Handbook of Macroeconomics, NorthHolland, p. 3-64, 2000.

TELES, V. K. et al. Ciclos econômicos e métodos de filtragem: "fatos estilizados" para o caso brasileiro. Economia, v. 6, n. 2, p. 291-328, jul.-dez. 2005. 


\section{Apêndice A - Variáveis Utilizadas na Análise e Testes de Raiz Unitária}

A Tabela 11 contém as estatísticas descritivas das principais variáveis analisadas neste artigo.

Tabela 11 - Estatísticas Descritivas das Principais Variáveis Usadas na Análise

\begin{tabular}{|c|c|c|c|c|c|c|}
\hline Variável & Unidade & Obs. & Média & Máximo & Mínimo & $\begin{array}{l}\text { Desvio } \\
\text { Padrão }\end{array}$ \\
\hline \multicolumn{7}{|l|}{$\begin{array}{c}\text { Medidas de } \\
\text { Produtividade }\end{array}$} \\
\hline TFPSTD & Índice & 65 & 10,100 & 10,354 & 99,865 & 0,117 \\
\hline TFPEE & Índice & 65 & 10,041 & 10,228 & 99,888 & 0,088 \\
\hline TFPUCI & Índice & 65 & 10,029 & 10,233 & 99,865 & 0,093 \\
\hline \multicolumn{7}{|l|}{$\begin{array}{c}\text { Medidas de Política } \\
\text { Monetária }\end{array}$} \\
\hline M1 & $\mathrm{R} \$ \mathrm{MM}$ & 65 & 1589,4 & 65648,58 & $1,03 \mathrm{E}-05$ & 21222,41 \\
\hline M2 & $\mathrm{R} \$ \mathrm{MM}$ & 65 & 9219,69 & 454334,9 & $4,05 \mathrm{E}-05$ & 132253,6 \\
\hline M3 & $\mathrm{R} \$ \mathrm{MM}$ & 65 & 128026,1 & 564183,5 & $6,9 \mathrm{E}-05$ & 175380 \\
\hline Taxa de Juros (Selic) & \%a.m. & 65 & 13,654 & 54,356 & 1,159 & 13,997 \\
\hline \multicolumn{7}{|l|}{ Medidas de Preço } \\
\hline IGP-DI & Índice & 65 & 61,893 & 194,556 & $5,78 \mathrm{E}-08$ & 73,291 \\
\hline IPCA & Índice & 65 & 593,548 & 1695,597 & $6,09 \mathrm{E}-07$ & 696,867 \\
\hline \multicolumn{7}{|l|}{$\begin{array}{c}\text { Medidas de Setor } \\
\text { Externo }\end{array}$} \\
\hline U.S. GDP & U\$ MM & 65 & 8128,94 & 9849,492 & 6693,792 & 912,939 \\
\hline $\begin{array}{l}\text { U.S. Int.Rate (Fed } \\
\text { Funds) }\end{array}$ & \%a.m. & 65 & 5,996 & 9,727 & 2,99 & 1,695 \\
\hline $\begin{array}{l}\text { U.S. Int.Rate (Long } \\
\text { Term) }\end{array}$ & \%a.m. & 65 & 7,26 & 11,583 & 4,67 & 1,489 \\
\hline \multicolumn{7}{|l|}{$\begin{array}{l}\text { Medidas de Insu- } \\
\text { mos de Produção }\end{array}$} \\
\hline Produção Industrial & Índice & 65 & 11,734 & 132,353 & 91,367 & 9,00 \\
\hline Estoque de Capital & $\mathrm{R} \$ \mathrm{MM}$ & 65 & 1608,872 & 1776,027 & 1435 & 92,218 \\
\hline $\begin{array}{l}\text { Estoque de } \\
\text { Capital*UCI }\end{array}$ & $\mathrm{R} \$ \mathrm{MM}$ & 65 & 1172,738 & 1466,957 & 759,211 & 154,767 \\
\hline
\end{tabular}

(continua) 
(continuação)

\begin{tabular}{c|c|c|c|c|c|c}
\hline $\begin{array}{c}\text { Consumo Ind. de } \\
\text { Energia }\end{array}$ & Mwh & 65 & 9132,304 & 11196,48 & 7388,565 & 936,059 \\
\hline Horas & Índice & 65 & 84,081 & 119,523 & 52,681 & 21,202 \\
\hline UCI & Índice & 65 & 0,728 & 0,874 & 0,477 & 0,066 \\
\hline
\end{tabular}

Nota:

(a) Período amostral : 1985:01/2001:01.

(b) Variáveis que exibiam padrões sazonais foram previamente dessazonalizadas.

Fonte: Elaborada pelo autor com base nos dados do Banco Central do Brasil (2004), Instituto Brasileiro de Geografia e Estatística (2004), Eletrobras (2004) e Fundação Getúlio Vargas (2004).

As Tabelas 12 a 15 contêm resultados de testes de raiz unitária. As Tabelas 12 e 13 contêm resultados relacionados aos testes ADF (DICKEY; FULLER, 1981) e PP (PHILLIPS; PERRON, 1988), enquanto que as Tabelas 14 e 15 contêm resultados relacionados ao teste KPSS (KWIATKOWSKI et al. 1992).

Tabela 12 - Testes de de Raiz Unitária (ADF e PP)

\begin{tabular}{|c|c|c|}
\hline Variável & ADF & PP \\
\hline Produção Industrial & $\begin{array}{c}-1,67 \\
(2)\end{array}$ & $\begin{array}{c}-2,71 \\
(2)\end{array}$ \\
\hline$\Delta$ (Produção Industrial) & $\begin{array}{c}-8,67^{* * *} \\
\text { (1) }\end{array}$ & $\begin{array}{c}-9,33^{* * *} \\
(5)\end{array}$ \\
\hline Horas & $\begin{array}{c}-4,09 * * \\
\text { (1) }\end{array}$ & $\begin{array}{c}-3,72^{* *} \\
(1)\end{array}$ \\
\hline$\Delta$ (Horas) & $\begin{array}{c}-4,95 * * * \\
\text { (1) }\end{array}$ & $\begin{array}{c}-4,91 * * * \\
\text { (3) }\end{array}$ \\
\hline Eletricidade & $\begin{array}{c}-3,53^{* *} \\
(0)\end{array}$ & $\begin{array}{c}-3,53^{* *} \\
(0)\end{array}$ \\
\hline$\Delta$ (Eletricidade $)$ & $\begin{array}{c}-7,47^{* * *} \\
(1)\end{array}$ & $\begin{array}{c}-1,48^{* * *} \\
(10)\end{array}$ \\
\hline UCI & $\begin{array}{c}-4,26 * * * \\
(0)\end{array}$ & $\begin{array}{c}-4,15^{* * *} \\
(2)\end{array}$ \\
\hline$\Delta(\mathrm{UCI})$ & $\begin{array}{c}-8,48^{* * *} \\
\text { (1) }\end{array}$ & $\begin{array}{c}-21,89 * * * \\
(27)\end{array}$ \\
\hline Capital & $\begin{array}{c}-2,9 \\
(1) \\
\end{array}$ & $\begin{array}{c}-1,92 \\
(6)\end{array}$ \\
\hline$\Delta$ (Capital) & $\begin{array}{c}-2,27 \\
(0) \\
\end{array}$ & $\begin{array}{c}-2,29 \\
(1)\end{array}$ \\
\hline$\Delta^{2}$ (Capital) & $\begin{array}{c}-8,15^{* * *} \\
(0)\end{array}$ & $\begin{array}{c}-8,15^{* * *} \\
\text { (1) }\end{array}$ \\
\hline $\mathrm{K}^{*} \mathrm{UCI}$ & $\begin{array}{c}-1,76 \\
(3)\end{array}$ & $\begin{array}{c}-5,67^{* * *} \\
\text { (1) }\end{array}$ \\
\hline
\end{tabular}

(continua) 


\begin{tabular}{c|c|c}
\hline$\Delta(\mathrm{K} * \mathrm{UCI})$ & $\begin{array}{c}-9,79^{* * *} \\
(2)\end{array}$ & $\begin{array}{c}-19,97^{* * *} \\
(17)\end{array}$ \\
\hline \multirow{2}{*}{ TFPSTD } & $-1,36$ & $-2,27$ \\
& $(2)$ & $(2)$ \\
\hline \multirow{2}{*}{$\Delta($ TFPSTD $)$} & $-9,3^{* * *}$ & $-1,8^{* * *}$ \\
& $(1)$ & $(7)$ \\
\hline \multirow{2}{*}{ TFPEE } & $-1,59$ & $-2,59$ \\
& $(2)$ & $(2)$ \\
\hline \multirow{2}{*}{$\Delta($ TFPEE $)$} & $-1,31^{* * *}$ & $-11,73^{* * *}$ \\
& $(1)$ & $(10)$ \\
\hline \multirow{2}{*}{ TFPUCI } & $-2,8$ & $-6,55^{* * *}$ \\
& $(3)$ & $(8)$ \\
\hline \multirow{2}{*}{$\Delta($ TFPUCI $)$} & $-14,23^{* * *}$ & $-21,9^{* * *}$ \\
& $(2)$ & $(13)$ \\
\hline
\end{tabular}

Notas:

(a) Período Amostral: 1985:01/2001:01.

(b) Todas as séries estão expressas na escala logarítmica natural, exceto pelas medidas de PTF e UCI.

(c) Valores críticos para esse teste estão contidos em Dickey e Fuller (1981) e Mackinnon (1991).

(d) O número de defasagens empregado em cada teste (reportado entre parênteses) foi escolhido de acordo com o critério de informação de Schwarz.

(d) Os termos $\left({ }^{*}\right),\left({ }^{* *}\right)$ e $(* *)$ denotam rejeição da hipótese nula de cada teste aos níveis de $10 \%$, $5 \%$ e $1 \%$ de significância, respectivamente.

Fonte: Elaborada pelo autor.

Tabela 13 - Testes de Raiz Unitária (ADF e PP)

\begin{tabular}{c|c|c}
\hline $\begin{array}{c}\text { Medidas de Política } \\
\text { Monetária }\end{array}$ & ADF & PP \\
\hline M1 & $\begin{array}{c}-0,64 \\
(3)\end{array}$ & $\begin{array}{c}0,15 \\
(4)\end{array}$ \\
\hline \multirow{2}{*}{$\Delta \mathrm{M} 1$} & $\begin{array}{c}-3,85^{* *} \\
(1)\end{array}$ & $\begin{array}{c}-3,01 \\
(7)\end{array}$ \\
\hline \multirow{2}{*}{$\Delta^{2} \mathrm{M} 1$} & $-7,39^{* * *}$ & $-13,37$ \\
& $(1)$ & $(61)$ \\
\hline \multirow{2}{*}{$\mathrm{M} 2$} & $-0,2$ & 0,22 \\
& $(2)$ & $(5)$ \\
\hline \multirow{2}{*}{$\Delta \mathrm{M} 2$} & $-3,17^{*}$ & $-2,33$ \\
$(1)$ & $(5)$ \\
\hline \multirow{2}{*}{$\Delta^{2} \mathrm{M} 2$} & $-5,69^{* * *}$ & $\begin{array}{c}-5,95^{* * *} \\
(18)\end{array}$ \\
\hline \multirow{2}{*}{$\mathrm{M} 3$} & $(0)$ & 0,25 \\
& $-0,33$ & $(5)$ \\
\hline
\end{tabular}




\begin{tabular}{|c|c|c|}
\hline$\Delta \mathrm{M} 3$ & $\begin{array}{c}-3,00 \\
(1) \\
\end{array}$ & $\begin{array}{c}-2,29 \\
(6) \\
\end{array}$ \\
\hline$\Delta^{2} \mathrm{M} 3$ & $\begin{array}{c}-6,17^{* * *} \\
(0)\end{array}$ & $\begin{array}{c}-7,25 \\
(27)\end{array}$ \\
\hline SELIC & $\begin{array}{c}-3,01 \\
(0)\end{array}$ & $\begin{array}{c}-2,93 \\
(5)\end{array}$ \\
\hline$\Delta$ SELIC & $\begin{array}{c}-8,47^{* * *} \\
(0)\end{array}$ & $\begin{array}{c}-11,73 \\
(18) \\
\end{array}$ \\
\hline \multicolumn{3}{|l|}{ Medidas de Inflação } \\
\hline IGP-DI & $\begin{array}{c}-0,44 \\
(2)\end{array}$ & $\begin{array}{c}0,23 \\
(5) \\
\end{array}$ \\
\hline$\Delta \mathrm{IGP}-\mathrm{DI}$ & $\begin{array}{c}-2,95 \\
(1) \\
\end{array}$ & $\begin{array}{c}-2,45 \\
(6) \\
\end{array}$ \\
\hline$\Delta^{2}$ IGP-DI & $\begin{array}{c}-6,64^{* * *} \\
(0)\end{array}$ & $\begin{array}{c}-7,65 * * * \\
(15)\end{array}$ \\
\hline IPCA & $\begin{array}{c}-0,44 \\
(2)\end{array}$ & $\begin{array}{c}0,31 \\
(5)\end{array}$ \\
\hline$\triangle \mathrm{IPCA}$ & $\begin{array}{c}-2,88 \\
(1) \\
\end{array}$ & $\begin{array}{c}-2,42 \\
(6) \\
\end{array}$ \\
\hline$\Delta^{2} \mathrm{IPCA}$ & $\begin{array}{c}-6,68^{* * *} \\
(0)\end{array}$ & $\begin{array}{c}-7,57^{* * *} \\
(18)\end{array}$ \\
\hline \multicolumn{3}{|c|}{ Medidas de Setor Externo } \\
\hline USRGDP & $\begin{array}{c}-1,55 \\
(1) \\
\end{array}$ & $\begin{array}{c}-1,48 \\
(4) \\
\end{array}$ \\
\hline$\Delta$ (USRGDP) & $\begin{array}{c}-5,66 * * * \\
(0)\end{array}$ & $\begin{array}{c}-5,7 * * * \\
\text { (2) }\end{array}$ \\
\hline Fed Funds Rate & $\begin{array}{c}-2,59 \\
(1)\end{array}$ & $\begin{array}{c}-1,87 \\
(4)\end{array}$ \\
\hline$\Delta($ Fed Funds Rate $)$ & $\begin{array}{c}-3,65^{* *} \\
(1)\end{array}$ & $\begin{array}{c}-3,75^{* *} \\
(2)\end{array}$ \\
\hline Long Term Rate & $\begin{array}{c}-4,3^{* * *} \\
(1)\end{array}$ & $\begin{array}{c}-3,68^{* * *} \\
(2)\end{array}$ \\
\hline$\Delta$ (Long Term Rate) & $\begin{array}{c}-5,19 * * * \\
(0)\end{array}$ & $\begin{array}{c}-5,17 * * * \\
(2)\end{array}$ \\
\hline
\end{tabular}

\section{Notas:}

(a) Período Amostral: 1985:01/2001:01.

(b) Todas as séries estão expressas na escala logarítmica natural, exceto pelas taxas de juros.

(c) Valores críticos para esse teste estão contidos em Dickey e Fuller (1981) e Mackinnon (1991).

O número de defasagens empregado em cada teste (reportado entre parênteses) foi escolhido de acordo com o critério de informação de Schwarz.

(d) Os termos $\left({ }^{*}\right),\left({ }^{* *}\right)$ e $(* * *)$ denotam rejeição da hipótese nula de cada teste aos níveis de $10 \%$, 5\% e 1\% de significância, respectivamente.

Fonte: Elaborada pelo autor. 
Tabela 14 - Testes de Raiz Unitária (KPSS)

\begin{tabular}{c|c|c}
\hline Variável & KPSS (4 defs.) & KPSS (8 defs.) \\
\hline Produção Industrial & $0,2^{* *}$ & $0,14^{*}$ \\
\hline Horas & $0,19^{* *}$ & $0,14^{*}$ \\
\hline Eletricidade & $0,2^{* *}$ & $0,16^{* *}$ \\
\hline UCI & $0,2^{* *}$ & $0,14^{*}$ \\
\hline Capital & $0,17^{* *}$ & 0,11 \\
\hline K*UCI & $0,18^{* *}$ & $0,13^{*}$ \\
\hline TFPSTD & $0,28^{* *}$ & $0,18^{* *}$ \\
\hline TFPEE & $0,28^{* * *}$ & $0,18^{* *}$ \\
\hline TFPUCI & $0,25^{* * *}$ & $0,18^{* *}$
\end{tabular}

Notas:

(a) Período Amostral: 1985:01/2001:01.

(b) Valores críticos para esse teste estão contidos em Kwiatkowski et al. (1992).

(c) Os termos $\left({ }^{*}\right),\left({ }^{* *}\right)$ e $\left({ }^{* * *}\right)$ denotam rejeição da hipótese nula de cada teste aos níveis de $10 \%, 5 \%$ e $1 \%$ de significância, respectivamente.

Fonte: Elaborada pelo autor.

Tabela 15 - Testes de Raiz Unitária (KPSS)

\begin{tabular}{c|c|c}
\hline $\begin{array}{c}\text { Medidas de Política } \\
\text { Monetária }\end{array}$ & KPSS(4 defs.) & KPSS(8 defs.) \\
\hline M1 & $0,28^{* * *}$ & $0,18^{* *}$ \\
\hline M2 & $0,29^{* * *}$ & $0,18^{* * *}$ \\
\hline M3 & $0,29^{* * *}$ & $0,18^{* *}$ \\
\hline SELIC & $0,2^{* *}$ & $0,15^{* *}$ \\
\hline Medidas de Inflação & & $0,19^{* *}$ \\
\hline IGP-DI & $0,3^{* * *}$ & $0,19^{* *}$ \\
\hline IPCA & $0,31^{* * *}$ & \\
\hline Medidas de Setor Externo & & $0,16^{* *}$ \\
\hline USRGDP & $0,24^{* *}$ & 0,11 \\
\hline Fed Funds Rate & $0,15^{* *}$ & 0,07 \\
\hline Long Term Rate & 0,06 & \\
\hline
\end{tabular}

Notas:

(a) Período Amostral: 1985:01/2001:01.

(b) Todas as séries estão expressas na escala logarítmica natural, exceto pelas taxas de juros.

(c) Valores críticos para esse teste estão contidos em Kwiatkowski et al. (1992). 
(d) O número de defasagens empregado em cada teste (reportado entre parênteses) foi escolhido de acordo com o critério de informação de Schwarz.

(e) Os termos $\left({ }^{*}\right),\left(^{* *}\right)$ e $(* * *)$ denotam rejeição da hipótese nula de cada teste aos níveis de $10 \%, 5 \%$ e $1 \%$ de significância, respectivamente.

Fonte: Elaborada pelo autor.

\section{Apêndice B - Derivação Formal do Resíduo de Solow}

Partindo de uma função de produção do tipo,

$$
Y(t)=A(t) F[K(t), L(t)]
$$

onde $Y(t)$ representa o montante de produto agregado, $K(t)$, o estoque de fator capital, e $L(t)$, a quantidade de fator trabalho, todas essas variáveis medidas em um dado instante $t$ de tempo. O termo $A(t)$ equivale a um índice do nível de tecnologia da economia.

Tomando logaritmos em ambos os lados de (B1), bem como derivando a expressão resultante em relação ao tempo $(t)$, obtemos:

$$
\dot{Y} / Y=\dot{A} / A+\left(A F_{K} K / Y\right)(\dot{K} / K)+\left(A F_{L} L / Y\right)(\dot{L} / L)
$$

Supondo a existência de um mercado competitivo para os fatores de produção, bem como a ocorrência de retornos constantes de escala, obtemos a seguinte expressão: ${ }^{19}$

$$
\dot{Y} / Y=\dot{A} / A+\alpha(t)(\dot{K} / K)+[1-\alpha(t)](\dot{L} / L)
$$

onde $\alpha(t)$ representa a participação do fator capital na renda total, com $[1-\alpha(t)]$ representando, portanto, a participação do fator trabalho. ${ }^{20}$ No caso de termos dados relativos a quantidades $(Y, K$, e $L)$ e preços

19 O fato do mercado de fatores de produção ser competitivo implica que o produto marginal de cada fator iguala seu preço, o que faz com que, em última instância, os termos $\left(A F_{K} K / Y\right)$ e $\left(A F_{L} L / Y\right)$ da expressão $(B 2)$ sejam equivalentes às parcelas de pagamento dos fatores capital e trabalho, respectivamente, em relação à renda total. Já a hipótese de retornos constantes de escala implica que as parcelas de pagamento dos fatores em relação à renda, quando somadas, igualam a unidade.

20 Vale notar que, ao se designar a participação do fator capital pelo termo $\alpha(t)$, considera-se a possibilidade de mudanças na participação dos fatores ao longo do tempo. Entretanto, no caso de uma função de produção do tipo Cobb-Douglas, a participação dos fatores é tida como constante. 
dos fatores (equivalentes às taxas de aluguel do capital e de salário do trabalho), tem-se que, de todas as variáveis da equação (B3), a única que não pode ser medida diretamente é a taxa de crescimento do índice tecnológico da economia $(\dot{A} / A)$. Colocando esta variável em função das demais, obtém-se:

$$
\dot{A} / A=\dot{Y} / Y-\{\alpha(t)(\dot{K} / K)+[1-\alpha(t)](\dot{L} / L)\}
$$

Ou seja, a taxa de crescimento de A nada mais é do que um "resíduo" da parte do crescimento do produto agregado que resta após serem subtraídas as taxas de crescimento dos fatores de produção (taxas estas, ponderadas por suas respectivas participações na renda agregada).

\section{Apêndice C - Metodologia de Cálculo do Impulso de Produtividade e Testes de Granger-Causalidade ${ }^{21}$}

O impulso de produtividade agregado é definido por Prescott (1986) como a variação na TFP. Assumindo-se uma função de produção Cobb-Douglas,

$$
Y_{t}=z_{t} K_{t}^{\alpha} N_{t}^{(1-\alpha)}
$$

temos que o choque de produtividade, $\mathrm{z}_{\mathrm{t}}$, pode ser medido a partir de dados agregados relacionados ao produto $(Y)$ e aos fatores de produção ( $\mathrm{K}$ e $N$ ), dado um valor específico para a participação do capital na renda $(\alpha)$.

Supondo-se adicionalmente que $z_{t}$ contenha uma raiz unitária em logaritmos, chegamos à seguinte representação:

$$
z_{t}=z_{t-1} \exp \left(\mu+\varepsilon_{t}\right), \operatorname{com} \varepsilon_{t}=\beta(L) \varepsilon_{t-1}+w_{t},
$$

onde $\varepsilon_{t}$ é uma variável aleatória estacionária, $\beta(L)$ representa um operador de defasagens e $w_{t}$ é uma variável aleatória não correlacionada serialmente e com média zero. Em Prescott (1986), $\varepsilon_{t}$ equivale à medida de choques de produtividade.

Uma hipótese comum aos primeiros modelos RBC é que $z_{t}$ é uma variável aleatória exógena. Assim, a distribuição de $z_{t}$ não deveria ser alterada por mudanças em outras variáveis macroeconômicas, como

Esta derivação do impulso de produtividade é baseada em Evans (1992, p. 193-195). 
aquelas relacionadas à política fiscal e à política monetária, por exemplo. Entretanto, caso $z_{\mathrm{t}}$ seja determinada endogenamente, então a omissão dessas variáveis macroeconômicas pode distorcer as estimativas de $z_{\mathrm{t}}$, colocando em dúvida a hipótese citada anteriormente.

Dada a especificação (C2), temos que a exogeneidade de $z_{t}$ requer que $\varepsilon$ também seja exógena.

A partir de (C1) e (C2), obtemos:

$$
\varepsilon_{t}=\Delta \log Y_{t}-\alpha \Delta \log K_{t}-(1-\alpha) \Delta \log N_{t}-\mu
$$

Dada uma estimativa desse impulso de produtividade agregado, $\varepsilon_{\mathrm{t}}$, temos que a hipótese básica de exogeneidade dessa estimativa em modelos RBC torna-se uma hipótese refutável estatisticamente, podendo ser testada a partir de testes-padrão de Granger-causalidade. Adicionalmente, temos que testes de exogeneidade permanecem válidos, mesmo no caso de não termos disponíveis medidas de outros choques reais em nossa amostra. Por exemplo, no caso de considerarmos modelos RBC com dois choques reais, $z_{t}$ e $\tau_{t}$, geradores de flutuações na economia $\mathrm{e}$ supondo que $\tau_{t}$ possa ser descrito pelo processo

$$
\log \tau_{t}=\rho \log \tau_{t-1}+v_{t}, \operatorname{com}|\rho|<1,
$$

onde $v_{t}$ equivale a uma variável aleatória com média zero. As inovações $v_{t}$ e $w_{t}$ constituem, por hipótese, um vetor de processos whitenoise, embora possam ser correlacionados contemporaneamente. Dada a especificação (C2), valores passados de $v$ não deveriam ajudar a prever $\varepsilon_{t}$, além dos valores passados dessa variável. Assim, a medida de impulso de produtividade $\varepsilon_{t}$ pode ser vista como uma variável que não pode ser prevista com base em valores de outras variáveis, sejam elas reais ou nominais, bem como no caso de outros choques reais omitidos da análise (representados por $v$, no caso). Uma forma de se testar essa hipótese é a partir da seguinte especificação:

$$
\varepsilon_{t}=\beta(L) \varepsilon_{t-l}+\alpha(L) x_{t-l}+w_{t}
$$

onde $\alpha(L)$ e $\beta(L)$ representam polinômios de defasagens. De acordo $\operatorname{com}(\mathrm{C} 2), x$ não deveria fornecer nenhum poder preditivo a $\varepsilon$. Um resultado que indique que $\alpha(L) \neq 0$ em (C4) passa a ser suficiente para que rejeitemos a hipótese de que $\varepsilon$ é estritamente exógeno. 
Para obtermos a medida de impulso de produtividade, procedemos da seguinte maneira: regredimos valores das medidas de TFP em seus valores defasados em um período e uma constante. Os resíduos obtidos a partir de regressões desse tipo representam as séries de impulsos de produtividade $\left(\varepsilon_{t}\right)$.

Recebido em: 15/01/2009.

Aceito em: 16/06/2009. 